\title{
PREVALENCE OF THEILERIOSIS AND BABESIOSIS IN CATTLE IN SIRAJGANJ DISTRICT OF BANGLADESH
}

\author{
Md. Abdullah-Al-Mahmud ${ }^{1 *}$, SM Shariful Hoque Belal' ${ }^{2}$ and Md. Alamgir Hossain ${ }^{3}$ \\ ${ }^{1}$ Additional Veterinary Surgeon, Upazila Livestock Office, Ullapara, Sirajganj; ${ }^{2}$ Veterinary \\ Surgeon, District Veterinary Hospital, Sirajganj; ${ }^{3}$ Department of Medicine, Sylhet \\ Agricultural University, Sylhet, Bangladesh \\ *Corresponding author: Md. Abdullah-Al-Mahmud; E-mail: dr.mahmud04@gmail.com
}

\section{ARTICLE INFO ABSTRACT}

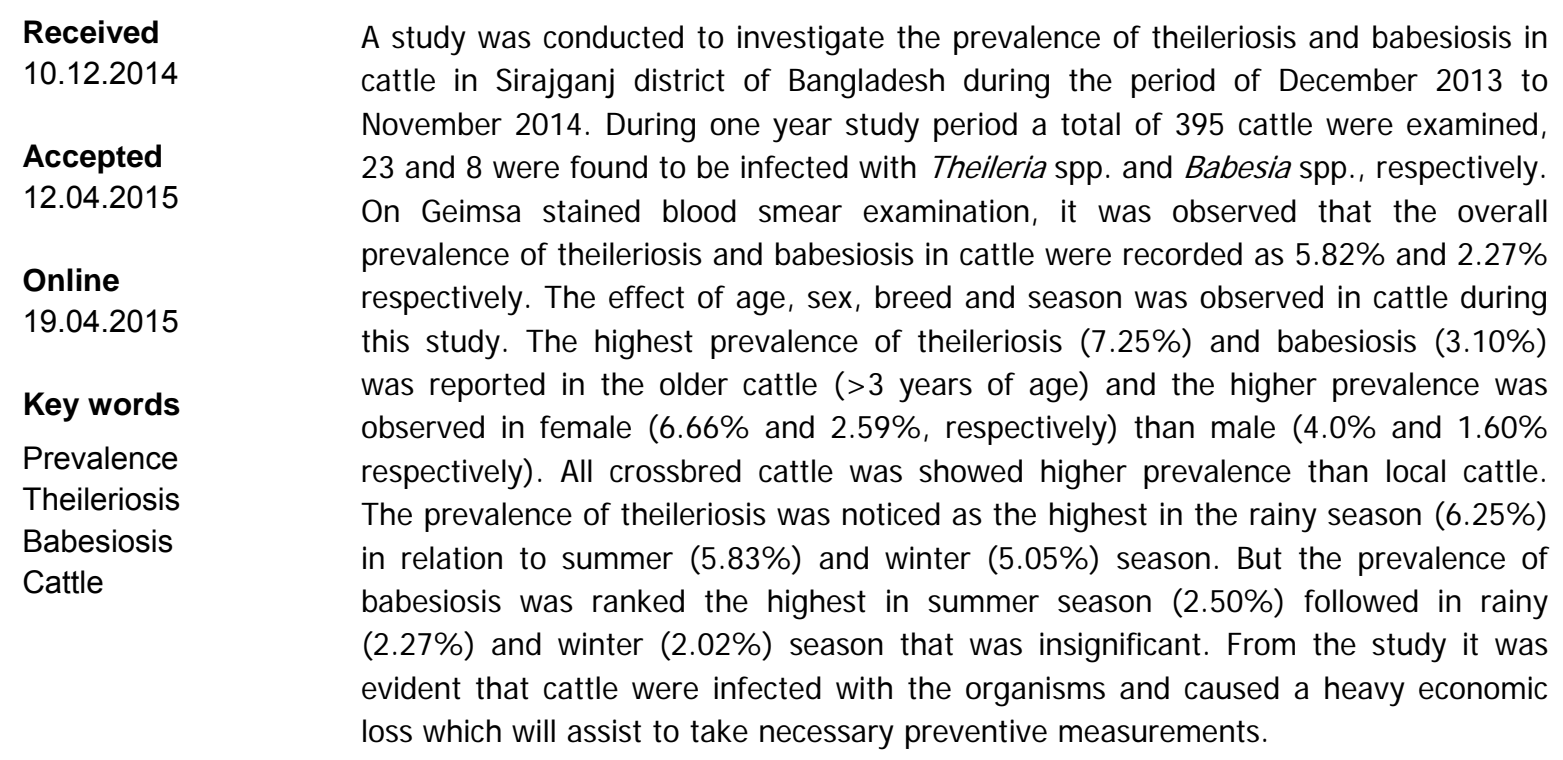

To cite this article: MAA Mahmud, SMSH Belal and MA Hossain. 2015. Prevalence of theileriosis and babesiosis in cattle in Sirajganj district of Bangladesh. Res. Agric. Livest. Fish. 2 (1): 79-86. 


\section{INTRODUCTION}

Babesiosis and Theileriosis are febrile, tick-borne haemoprotozoan diseases of cattle, caused by Babesia spp. and Theileria spp. respectively, wide spread in tropical and sub-tropical regions of the world. Among tickborne hemoprotozoan parasites of vertebrates Theileria and Babesia are the species that have a major effect on livestock health (Mehlhorn and Schein, 1984). Babesiosis, like most haemoparasites, has generally been shown to cause destruction of red blood cells resulting in anaemia, jaundice, anorexia, weight loss and infertility (Ellis et al., 2003); and Theileria sp.is a common protozoan parasite of cattle transmitted by Hyalomma sp. ticks, responsible for tropical theileriosis, a disease which has been reported from various parts of the world (Oliveira et al., 1995; Durrani et al., 2010; Tavassoli et al., 2011). Tick-borne diseases cause substantial losses to the livestock industry throughout the world (Ananda et al., 2009; Kakarsulemankhel, 2011) as these have got a serious economic impact due to obvious reason of death, decreased productivity, lowered working efficiency (Uilenberg, 1995), increased cost for control measures (Makala et al., 2003) and limited introduction of genetically improved cattle in an area (Radostits et al., 2000).

Bangladesh is usually hot and humid except in winter, and the climatic condition of Bangladesh is very conducive to a wide variety of parasites as well as ticks (Razzak and Shaikh, 1969) which have been recognized as the notorious threat due to severe irritation, allergy and toxicosis (Niyonzema and Kiltz, 1986). Prevalence of blood protozoa such as Babesia bigemina, Theileria annulata, Theileria mutans has been reported in animals of Bangladesh (Ahmed, 1976; Samad and Gautam, 1984); where Alim et al. (2012) observed that the prevalence of theileriosis and babesiosis was $4.62 \%$ and $1.85 \%$, respectively in Noakhali district, and $8.33 \%$ and $2.78 \%$, respectively in Khagrachori district. Chowdhury et al. (2006) recorded the prevalence of Babesia bigemina infection in cattle was $3.30 \%$ in Sirajganj sadar area of Bangladesh. Outbreaks of clinical illness do not occur uniformly in tick-infected areas due to the differences in genetic or age resistance of the cattle, variations in tick populations, numbers of infected ticks and established control methods (de Castro, 1997). Kamani et al. (2010) observed that the higher prevalence was found in adult than young cattle. Sarkar (2007) and Khattak et al. (2012) also found that the higher prevalence was showed in female than male. Prevalence of the disease was higher in croosbreed cattle than local cattle which was reported by Siddiki et al. (2010) and Esin et al. (2012). Seasonal variation on tick infestation was reported by Zahid et al., (2005) and Sanjay et al. (2007) where they reported that the prevalence of tick infestation was significantly more during the rainy season. Sirajganj is the most important dairy belt of Bangladesh and the density of cattle population of this district is high. The climatic condition and geographical location of the areas might favor the growth and multiplication of of ticks which act as natural vectors of babesiosis and theileriosis that causes one of the major veterinary problems affecting livestock industries. Considering the above situations, the present research was undertaken to know the prevalence of babesiosis and theileriosis of cattle in Sirajganj district of Bangladesh.

\section{MATERIALS \& METHODS}

\section{Geographical location of study area}

Sirajganj district is situated in Rajshahi Division of Bangladesh; its geographical coordinates are $24^{\circ} 27^{\prime} 0^{\prime \prime}$ North, 89 $43^{\circ} 0^{\prime \prime}$ East. Sirajganj has an area of 2,498 sq.km (964 sq miles) including reverine areas, and it represents around 1.7 percent of the total area of Bangladesh. It ranks $3^{\text {rd }}$ in size among the eight districts of Rajshahi division and $25^{\text {th }}$ among the 64 districts of Bangladesh. It contains 9 upazilas namely SirajganjSadar, Shahjadpur, Ullapara, Kamarkhand, Belkuchi, Chouhali, Raigonj, Tarash and Kazipur.The annual average temperature of the district reaches a maximum of $34.6^{\circ} \mathrm{C}$, and a minimum of $11.9^{\circ} \mathrm{C}$. The annual rainfall is $1610 \mathrm{~mm}$ (63.4 in).

\section{Experimental animals and duration of study}

This research work was conducted at the Field Diseases Investigation Laboratory (FDIL), Sirajganj on the clinical cases in cattle during the period from December 2013 to November 2014. During one year study period, a total of 395 case of sick and suspected cattle were studied that was informed by farmers, Veterinary Field Assistant, Veterinary Surgeon and Upazila Livestock Officer of respective upazila of Sirajganj district. 
Only 23 and 9 cattle were infected byTheileria spp and Babesia spp. among 395 suspected cases. Date, age, sex, breed and complaint of the owner of all studied animal were noted in the registered book. All this information and data were collected from the disease register book of the FDIL, Sirajganj.

\section{Methods followed for diagnosis}

The history and physical examination of each of the patient were carried out for the cattle are briefly described below:

\section{HistorylAnamnesis}

History of patient like (a) Date of examination, (b) Signalment (client and patient) identification, (c) Chief complaint, (d) Patient illness, (e) Past medical history were included. In addition, the complete medical history like (a) Family medical history, (b) Vaccination history, (c) Travel history, (d) Diet history, (f) Environmental history, (g) Birth history (h) Potential source of intoxication were investigated.

\section{Physical examination}

Physical examination was done by visual inspection, pulse \& respiration rate and rectal temperature. Examination of the different organs and systems of the body was carried out by using the clinical methods of palpation, percussion and auscultation.

\section{Sample collection and examination}

3-5 $\mathrm{ml}$ blood samples were collected from the jugular vein of the clinically suspected animals in EDTA containing vacutainers and transported to FDIL, Sirajganj in ice bags for microscopic examination following the method of Adam, Paul and Zaman. Briefly, a thin blood smear was prepared from each blood sample, air dried and fixed in methanol for 2-3 minutes. Staining was done in $5 \%$ Giemsa's stain and rinsing was performed in two changes of distilled water buffered to $\mathrm{pH} 7.2$, then examined under microscope (100x) with immersion oil for the identification of blood parasites as described by Soulsby (1982).

\section{Statistical analysis}

Data were entered in Microsoft Excel 2007 and transferred to R 2.14.2 (The R Foundation for Statistical Computing, Vienna, Austria). Descriptive statistics were obtained using Data Mining package of the software R 2.14.2

\section{RESULTS AND DISCUSSION}

\section{Overall prevalence of theileriosis and babesiosis in cattle}

Overall prevalence of theileriosis and babesiosis of cattle in Sirajganj district is shown in table 1. The overall prevalence of Theileriosis and Babesiosis of cattle in Sirajganj district was $5.82 \%$ and $2.27 \%$ respectively. The present study supports with the report of Khattak et al. (2012) who observed that the overall prevalence of Theileriosis on Giemsa stain was $5.20 \%$ in Khyber PukhtoonKhwa province (Pakistan). Similar results were also observed by Mohammed Safieldin et al. (2011) who found that the prevalence of Theileria species infection in dairy cattle in Omdurman locality, Sudan was found to be $7 \%$ for dry cool season while the prevalence of Babesia species infection was $1 \%$. In Bangladesh, similar findings were also reported by Alim et al. (2012) where he observed that the prevalence of theileriosis and babesiosis was $4.62 \%$ and $1.85 \%$ respectively in Noakhali district, and $8.33 \%$ and $2.78 \%$ respectively in Khagrachori district.Babesia infection $(2.27 \%)$ recorded in this study is similar to the report of Shahidullah (1983) who recorded the prevalence of babesiosis was $2.29 \%$ on microscopic peripheral blood smear examination. Samad et al. (1989) and Chowdhury et al. (2006) recorded a comparatively higher (3.28\% and $3.30 \%$ respectively) prevalence of Babesia bigemina infection in cattle of the selected Milk vita project areas of Bangladesh and Sirajganj sadar area of Bangladesh respectively. But Banerjee et al. (1983) detected very high $(14.53 \%)$ prevalence of Babesia bigemina in cattle of Bangladesh. 
Table 1. Overall prevalence of theileriosis and babesiosis of cattle in Sirajganj district

\begin{tabular}{|lccc|}
\hline Name of Diseases & $\begin{array}{c}\text { No. of cattle tested } \\
\text { (for both diseases) }\end{array}$ & No. of positive case & Prevalence (\%) \\
Theileriosis & 395 & 23 & 5.82 \\
Babesiosis & & 9 & 2.27 \\
\hline
\end{tabular}

\section{Age-wise prevalence}

Age-wise prevalence of Theileriosis and Babesiosis in cattle is shown in table 2. Age also influences the occurrence of the infections. The highest prevalence of Theileriosis and Babesiosis was found in the age of above 3 years $(7.25 \%$ and $3.10 \%$ respectively), followed in $>2-3$ years $(5.12 \%$ and $1.70 \%$ respectively) and 6 months -2 years of age (3.52\% and $1.17 \%$ respectively).Similar results were found byKamani et al. (2010) who observed higher prevalence in adult than young cattle. The results of present study agree with Islam et al. (2009) who found that prevalence of tick infestation was higher in old cattle than young. Observation of this study also supported by the findings of of Ananda et al. (2009) who reported higher prevalence in animals aged more than 3 years followed by the lower prevalence in 1-2 years of age. Findings of babesiosis in this investigation were supported by the observation of Urquhart et al. (1996) and Annetta et al. (2005) who reported an inverse age resistance of the disease where adult showed more susceptibility than calves. This might be due to rapid immune responses to primary infection by the calves through a complex immune mechanism (Annetta et al., 2005). Endemic instability of the study areas might responsible for frequent infections in adult cattle where newborn calves were protected by colostral immunity (Cynthia et al., 2011). Age resistance, perhaps in combination in some cases with maternal antibodies, is reflected in the reduced number of clinical outbreaks in young animals.

Table 2. Age-wise prevalence of theileriosis and babesiosis in cattle

\begin{tabular}{|lccccc|}
\hline Age group & $\begin{array}{l}\text { No. of cattle } \\
\text { tested }\end{array}$ & $\begin{array}{l}\text { Theileriosis } \\
\text { No. }\end{array}$ & $\begin{array}{l}\text { Babesiosis } \\
\text { No. }\end{array}$ & \% \\
\hline 6 months-2 years & 85 & 3 & 3.52 & 1 & 1.17 \\
>2-3 years & 117 & 6 & 5.12 & 2 & 1.70 \\
Above 3 years & 193 & 14 & 7.25 & 6 & 3.10 \\
Total & $\mathbf{3 9 5}$ & $\mathbf{2 3}$ & $\mathbf{5 . 8 2}$ & $\mathbf{9}$ & $\mathbf{2 . 2 7}$ \\
\hline
\end{tabular}

\section{Sex-wise prevalence}

Sex-wise prevalence of Theileriosis and Babesiosis in cattle is shown in table 3. In case of both Theileriosis and Babesiosis, the higher prevalence was observed in female $(6.66 \%$ and $2.59 \%$ respectively) than male (4.0\% and $1.60 \%$ respectively). Similar findings were found by Singh et al. (2012) and Khattak et al. (2012) where they separately observed that the prevalence of theileriosis was higher in female than male. This result also agree with the report of Sarkar (2007) who reported the prevalence of ectoparasites (ticks) were significantly higher in female than male. The prevalence of hemoprotozoan diseases in female cattle of this investigation showed uniformity with the report of Kamani et al. (2010). Higher prevalence in female cattle possibly due the fact that they were kept longer for breeding and milk production purpose, supplied insufficient feed against their high demand (Kamani et al., 2010) or variation in sample size.

Table 3. Sex-wise prevalence of Theileriosis and Babesiosis in cattle

\begin{tabular}{|llcccc|}
\hline Sex group & $\begin{array}{l}\text { No. of cattle } \\
\text { tested }\end{array}$ & $\begin{array}{l}\text { Theileriosis } \\
\text { No. }\end{array}$ & $\mathbf{( \% )}$ & Babesiosis & No. \\
\hline Male & 125 & 5 & 4.0 & 2 & 1.60 \\
Female & 270 & 18 & 6.66 & 7 & 2.59 \\
Total & 395 & $\mathbf{2 3}$ & $\mathbf{5 . 8 2}$ & $\mathbf{9}$ & $\mathbf{2 . 2 7}$ \\
\hline
\end{tabular}




\section{Breed-wise prevalence}

Breed-wise prevalence of Theileriosis and Babesiosis in cattle is shown in table 4 . The highest prevalence of Theileriosis was recorded in $\mathrm{HF} \times \mathrm{L}(6.66 \%)$ followed by $\mathrm{SL} \times \mathrm{L}(6.18 \%)$, $S \times \mathrm{L}(5.55 \%)$ and local $(4.54 \%)$. In case of Babesiosis, the highest prevalence was reported in $\mathrm{HF} \times \mathrm{L}(2.50 \%)$ followed by local $(2.27 \%), \mathrm{S} \times \mathrm{L}$ $(2.22 \%)$ and $S L \times L(2.06 \%)$. In the present study, higher prevalence of Theileria infections in crossbreed cattle as compared to local cattle was found. Breed differences are also important in the susceptibility of cattle to tick borne diseases. Cattle of European origin like Holstein are usually highly susceptible (Esin et al. 2012). Breed susceptibility of Babesiosis also recorded in this study support the report of Chakraborti A, (2002). Variation in geo-climatic condition, breed, and exposure of vectors and age of the animals might contribute to variable prevalence of hemoprotozoan diseases in the study areas (Muhanguzi et al., 2010). Constant exposure of infections and development of immunity against such infections might responsible for lower prevalence in indigenous cattle (Siddiki et al., 2010). On the contrary, more attention in the management of HF crossbred cattle gives less chance of pre exposure of vectors and develop no or less immunity, resulting frequent occurrence of such diseases (Chowdhury et al., 2006; Ananda et al., 2009; Siddiki et al., 2010).

Table 4. Breed-wise prevalence of Theileriosis and Babesiosis in cattle

\begin{tabular}{|llllll|}
\hline Breed & $\begin{array}{l}\text { No. of cattle } \\
\text { tested }\end{array}$ & $\begin{array}{l}\text { Theileriosis } \\
\text { No. }\end{array}$ & $\%$ & $\begin{array}{l}\text { Babesiosis } \\
\text { No. }\end{array}$ \\
\hline Local & 88 & 4 & 4.54 & 2 & 2.27 \\
$\mathrm{HF} \times \mathrm{L}$ & 120 & 8 & 6.66 & 3 & 2.50 \\
$\mathrm{SL} \times \mathrm{L}$ & 97 & 6 & 6.18 & 2 & 2.06 \\
$\mathrm{~S} \times \mathrm{L}$ & 90 & 5 & 5.55 & 2 & 2.22 \\
Total & $\mathbf{3 9 5}$ & $\mathbf{2 3}$ & $\mathbf{5 . 8 2}$ & $\mathbf{9}$ & $\mathbf{2 . 2 7}$ \\
\hline
\end{tabular}

Local=Indigenous cattle, HF = Holstein-Friesian, SL = Sahiwal, $S=$ Sindhi, L= Local cattle

Table 5. Season-wise prevalence Theileriosis and Babesiosis in cattle

\begin{tabular}{|lclccc|}
\hline Season & $\begin{array}{c}\text { No. of cattle } \\
\text { tested }\end{array}$ & $\begin{array}{c}\text { Theileriosis } \\
\text { No. }\end{array}$ & $\mathbf{\%}$ & No. & \%abesiosis \\
\hline Summer & 120 & 7 & 5.83 & 3 & 2.50 \\
Rainy & 176 & 11 & 6.25 & 4 & 2.27 \\
Winter & 99 & 5 & 5.05 & 2 & 2.02 \\
Total & $\mathbf{3 9 5}$ & $\mathbf{2 3}$ & $\mathbf{5 . 8 2}$ & $\mathbf{9}$ & $\mathbf{2 . 2 7}$ \\
\hline
\end{tabular}

Summer: March- June; Rainy: July-October and Winter: November-February

\section{Season-wise prevalence}

Season-wise prevalence of Theileriosis and Babesiosis in cattle in the study area is shown in table 5 . The prevalence of Theileriosis was ranked the highest in rainy season $(6.25 \%)$ in relation to summer $(5.83 \%)$ and winter $(5.05 \%)$ season. But the prevalence of Babesiosis was observed the highest in summer season $(2.50 \%)$, followed by rainy $(2.27 \%)$ and winter $(2.02 \%)$ season. Occurrence of theileriosis was found in line with the reports of Muhammad et al. (1999) and Zahid et al. (2005). Observation of rainy season of this research was in accordance with the report of Ananda et al. (2009). Radostits et al. (2000) observed that higher incidence of haemoprotozoan diseases were found soon after peck of tick population depending on temperature, humidity, rainfall etc. which might be accounted for higher prevalence of such infections in rainy season of the study. Lower temperature and humidity of winter months were less favorable for the growth and multiplication of tick vectors which might contribute to lower frequency of such diseases in the study population (Muhammad et al., 1999; Zahid et al., 2005). Salih et al. (2008) found the highest number of ticks occur during the rainy season. Sanjay et al. (2007) also reported the seasonal prevalence of tick infestation significantly more during the rainy $(24.33 \%)$ and summer seasons $(21.58 \%)$ as compared to the winter season 
(4.03\%). This variation may be due to geographical location, climatic condition, reproduction of tick and tick population. The present study recorded a higher prevalence of Babesiosis in summer season which was agreed with the report of Rony et al. (2010) where he noticed that the prevalence of ectoparasites/ tick infestation was higher in summer season. The rise of infestation in summer may be due to rise of temperature in late winter leading to gradual increase in the load as well as percentage of infestation in May and June (Roy et al. 2001).

Tick transmitted haemoprotozoan diseases especially babesiosis, theileriosis and anaplasmosis are considered some of the major impediments in the health and productive performance of cattle (Rajput et al., 2005); affecting livestock industries in many parts of the world (Hourrigan, 1979). In some cases, ticks have been reported to cause lowered productivity, mortality (Niyonzema and Kiltz, 1986) and transmit the diseases (Norval et. al., 1984). Haemoprotozoan diseases of cattle have also been recorded from some districts of Bangladesh (Samad et al. (1983); which are one of the major constraints for profitable dairy industry in tropical and subtropical countries including Bangladesh.Theileria and Babesia species are among the major piroplasms of cattle and small ruminants (Uilenberg, 1995; Gubbels et al., 1999; Oura et al., 2004; Oura et al., 2005); which cause significant economic losses in tropical and sub-tropical regions of the world (Uilenberg, 1995; Kursat et al., 2004; Jongejan and Uilenberg, 2004).

From the above discussion it is concludate that the prevalence of theileriosis and babesiosis is the most common and frequent in Sirajganj district of Bangladesh which may be due to its agro-ecological and geoclimatic conditions, high density of cattle population, lowland/flood plain based area and high density of tick population. So, for the control and eradication of the diseases in cattle population of Bangladesh specially Sirajganj district, epidemiological surveillance is the important aspect along with more attention should be paid towards separation of healthy and infected animals/herds and strictly followed with biosecurity in cattle farm. Reduction of tick population and tick's reproduction is the main issue for control of the diseases. This should be combined with more government intervention in with awareness program should be undertaken involving stakeholders in the livestock industry as well as consumers to avert public health, veterinary public health and economic losses associated with the mentioned diseases.

\section{REFERENCE}

1. Ahmed AKNU, 1976. Blood parasites of domestic animals in Bangladesh. Bangladesh Veterinary Journal, 10: 69-71.

2. Ananda KJ, PE Souza and GC Puttalakshmamma, 2009. Prevalence of haemoprotozoan diseases in crossbred cattle in Banglore north. Veterinary World, 2: 15-16.

3. Annetta ZS, Jeremy, Gray, E Helen, Skerrett and G Mulcahy, 2005. Possible mechanisms underlying age-related resistance to Bovine babesiosis. Parasite Immunology, 27: 115-120.

4. Alim MA, D Shubhagata, R Krisna, M Masuduzzaman, S Suchandan, H Mahmudul, AZ Siddiki and

5. MA Hossain, 2011. Prevalence of hemoprotozoan diseases in cattle population of Chittagong Division, Bangladesh. Pakistan Veterinary Journal, 32: 221-224.

6. Banerjee DP, KD Prasad and MA Samad, 1983. Seroprevalence of Babesia bigemina infection in cattle of India and Bangladesh. Indian Journal of Animal Sciences, 53: 431-433.

7. Chakraborti A, 2002. A Textbook of Preventive Veterinary Medicine. $3^{\text {rd }}$ end.,Kalyani Publishers, New Delhi. pp. 683.

8. Chowdhury S, MA Hossain, SR Barua and S Islam, 2006. Occurrence of common blood parasites of cattle in Sirajganj sadar area of Bangladesh. Bangladesh Journal of Veterinary Medicine, 4: 143-145.

9. Cynthia M, MA Kahn, S Line, E Susan and BS Aiello, 2011. Marck Veterinary Manual, Online Ed. Merck Sharp \& Dohme Corp, a subsidiary of Merck \& Co., Inc. Whitehouse Station, NJ, USA.

10. De Castro JJ, 1997. Sustainable tick and tick-borne disease control in livestock improvement in developing countries. Veterinary Parasitology, 77: 77-97.

11. Durrani AZ, N Mehmood and AR Shakoori, 2010. Comparison of three diagnostic methods for Theileria annulatedin Sahiwal and Friesian cattle in Pakistan. Pakistan Journal of Zoology, 42: 467472.

12. Ellis JT, DA Morrison, MP Reichel, 2003. Genomics and its impact on parasitology and the potential for development of new parasite control methods. DNA. Cellular Biology, 32: 395-403. 
13. Esin G, C Ayşe, O Omer, A Aytaç and K Asiye, 2012. Prevalence of Babesia bigemina and Theileria annulata in cattle in Eregli, Turkey. Harran Üniversitesi Veteriner Fakültesi, 1: 18-21

14. Gubbels JM, MAP Devos, J Van Der Weide, LM Viseras, E Schouls, Devries and F Jongejan, 1999. Simultaneous detection of bovine Theileria and Babesia species by reverse line blot hybridization. Journal of Clinical Microbiology, 1782-1789.

15. Hourrigan JL, 1979. Spread and detection of Psoroptic scabies of cattle in the United States. Journal of American Veterinary Association, 175: 1278-1280.

16. Islam MS, SA Rahman, $P$ Sarker, Anisuzzaman and MMH Mondal, 2009. Prevalence and population density of ectoparasitic infestation in cattle in Sirajgonj district, Bangladesh. Bangladesh Research Publications Journal. 2: 332-339.

17. Jongejan F, and G Uilenberg, 2004. The global importance of ticks. Parasitology 129: 3-14.

18. Kakarsulemankhel JK, 2011. Re-description of existing and description of new record of tick [Hyalomma (Euhyalomma) schulzei] from Pakistan. International Journal of Agriculture and Biology, 13: 689-694.

19. Kamani J, A Sannusi, OK Eqwu, GI Dogo, TJ Tanko, S Kemza, AE Takarki and DS Gbise, 2010. Prevalence and significance of haemoparasitic infections of cattle in North-Central, Nigeria. Veterinary World, 3: 445-448.

20. Khattak RM, M Rabib, Z Khan, M Ishaq, H Hameed, A Taqddus, M Faryal, S Durranis, Gillani Qua, R Allahyar, RS Shaikh, MA Khan, M Ali and F Iqbal, 2012. A Comparison of two different techniques for the detection of blood parasite, Theileria annulata in cattle from two districts in Khyber Pukhtoon Khwa province (Pakistan). Parasite, 19: 91-95

21. Kursat A, D Nazir, J Patricia, B Holman and A Munir, 2004. Detection of Theileria ovis in naturally infected sheep by nested PCR. Veterinary Parasitology, 127: 99-104.

22. Mehlhorn H, E Schein, 1984. The piroplasms: life cycle and sexual stages. AdvParasitol. 23: 37-103.

23. Mohammed Safieldin A, AGE Atif, and EH Khitma, 2011. Factors affecting seasonal prevalence of blood parasites in dairy cattle in Omdurman locality, Sudan. Journal of Cell and Animal Biology, 5 : 17-19.

24. Muhanguzi D, K Ikwap, K Picozzi and C Waiswa, 2010. Molecular characterization of anaplasma and ehrlichia species in different cattle breeds and age groups in Mbarara district (Western Uganda).International Journal of Animal and Veterinary Advance, 2: 76-88.

25. Makala LH, P Mangani, K Fujisaki and H Nagasawa, 2003. The current status of major tick borne diseases in Zambia. Veterinary Research, 34: 27-45.

26. Muhammad GM, M Saqib, MZ Athar and MN Khan, 1999. Clinico epidemiological and therapeutic aspects of bovine theileriosis. Pakistan Veterinary Journal, 19: 64-69.

27. Niyonzema A and HH Kiltz, 1986. Control of ticks and tick-borne diseases in Burundi. Australian Center for International Agricultural Research, 17:16-17.

28. Norval RAI, BH Fivaz, JA Lawrence and AF Brown, 1984. Epidemiology of tick-borne diseases of cattle in Zimbabwe. Tropical Animal Health and Production, 16: 63-70.

29. Oliveira DC, M Van Der Weide, MA Habela, $P$ Jacquiet and F Jongejan, 1995. Detection of Theileria annulatain blood samples of carrier cattle by PCR. Journal of Clinical Microbiology, 33: 2665-2669.

30. Oura CAL, R Bishop, EM Wampande, GW Lubega and A Tait, 2004. The persistence of component Theileria parva stocks in cattle immunized with the 'Muguga cocktail' live vaccine against East Coast fever in Uganda. Parasitology, 129: 27-42.

31. Oura CAL, BB Asiimwe, W Weir, GW Lubega and A Tait, 2005. Population genetic analysis and Substructuring of Theileria parva in Uganda. Mol. Biochem. Parasitol. 140: 229-239.

32. Razzak $A$ and $H$ Shaikh, 1969. A survey on the prevalence of ticks on cattle in East Pakistan. Pakistan Journal of Veterinary Science, 3: 54-60.

33. Rajput ZI, Hu Song-hua, AG Arijo, H Habib and K Khalid, 2005. Comparative study of Anaplasma parasites in tick carrying buffaloes and cattle. Journal of Zhejiang University Science, 6: 1057-1062.

34. Radostits OM, DC Blood and CC Gay, 2000. Veterinary Medicine: A text book of disease of cattle, sheep, pigs, goats and horse. 9th Ed, BaillereTindall Publication, London, pp: 1172-1173, 1289-1290. 
35. Rony SA, MMH Mondal, N Begum, MA Islam and S Affroze, 2010. Epidemiology of ectoparasitic infestations in cattle at Bhawal forest area, Gazipur. Bangladesh Journal of Veterinary Medicine, 8: 27-33.

36. Roy AK, MH Rahman, S Majumder and AS Sarker, 2001. Ecology of ticks and tick-borne blood protozoa in Madhupur Forest Area, Tangail. Bangladesh Veterinary Journal, 17: 90-97.

37. Samad MA and OP Goutam, 1984. Prevalence of Theileria annulata infection in cattle of Bangladesh. Indian Journal of Parasitology, 7: 61-63.

38. Samad MA, SA Bashar, M Shahidullah and MU Ahmed, 1989. Prevalence of haemoprotozoan parasites in cattle of Bangladesh. Indian Journal of Veterinary Medicine, 13: 50-51.

39. Samad MA, 2000. An overview of livestock research reports published during the twentieth century in Bangladesh. Bangladesh Veterinary Journal, 34: 53 -149.

40. Sanjay K, KD Prasad and AR Deb, 2007. Seasonal prevalence of different ectoparasites infecting cattle and buffaloes. Journal of Research, 16: 159-163.

41. Sarkar M, 2007. Epidemiology and pathology of ectoparasitic infestation in Black Bengal Goats in Bangladesh. M.Sc. thesis. Department of Parasitology, Bangladesh Agricultural University, Mymensingh.

42. Salih DA, II Julia, SM Hassan, AM El-Hussain and F Jongejan, 2008. Preliminary Survey of ticks (Acari: Ixodidae) on Cattle in Central Equatoria State, Southern Sudan.Onderstepoort Journal of Veterinary Research, 75: 47-53.

43. Shahidullah, 1983. Studies on haemoprotozoan disease of goats and cattle with their vector ticks. M. Sc. Thesis, Submitted to the Department of Medicine, Bangladesh Agricultural University, Mymensingh.

44. Singh NK, S Harkirat, Jyoti, M Haque, SS Rat, 2012. Prevalence of parasitic infections in cattle of Ludhiana district, Punjab. Journal of Parasitic Diseases, 36: 256-259.

45. Siddiki AZ, MB Uddin, Hasan, MF Hossain, MM Rahman, BC Das, MS Sarker and MA Hossain, 2010. Coproscopic and haematological approaches to determine the prevalence of Helminthiasis and protozoan diseases of Red Chittagong Cattle (RCC) breed in Bangladesh. Pakistan Veterinary Journal, 30: 1-6.

46. Tavassoli1 M, M Tabatabaei, BE Nejad, MH Tabatabaei, A Najafabadi and SH Pourseyed, 2011. Detection of Theileria annulata by the PCR-RFLP in ticks (Acari, Ixodidae) collected from cattle in west and North West Iran. Acta Parasitologica, 56: 8-13.

47. Uilenberg G, 1995. International collaborative research: significance of tick-borne hemoparasitic disease to world animal health. Veterinary Parasitology, 57: 19-41.

48. Zahid IA, M Latif and KB Baloch, 2005. Incidence and treatment of theileriasis and babesiasis. Pakistan Veterinary Journal, 25: 137-139. 